\title{
Pengaruh Motor Cognitive Coordination Training Terhadap Motor Coordination dan Working Memory Pada Atlet Junior
}

Muchamad Rizki Sentani ${ }^{\bowtie}$, Tatang Muhtar dan Agus Mahendra Pendidikan Olahraga,Universitas Pendidikan Indonesia, Bandung, Indonesia.

\begin{tabular}{|c|c|}
\hline & Abstract \\
\hline \multicolumn{2}{|l|}{$\begin{array}{l}\text { Kata Kunci: } \\
\text { Interval training, latihan, otot, } \\
\text { pemulihan, }\end{array}$} \\
\hline & $\begin{array}{l}\text { Tujuan dari penelitian ini untuk mengetahui apakah ada } \\
\text { pengaruh dari program permainan motor cognitive coordination } \\
\text { training terhadap motor coordination dan working memory. Metode } \\
\text { penelitian ekperimen dengan desain pretest-posttest control group } \\
\text { design digunakan dalam penelitian ini. Hasil penelitian menunjukan } \\
\text { bahwa program latihan motor cognitive coordination training } \\
\text { memiliki pengaruh yang signifikan terhadap motor coordination dan } \\
\text { working memory pada atlet junior. Selanjutnya pelatih menggunakan } \\
\text { program latihan motor cognitive coordination training untuk } \\
\text { meningkatkan performa motor skill dan cognitive skill pada atlet } \\
\text { junior. }\end{array}$ \\
\hline
\end{tabular}

\section{Abstract}

The purpose of this study is to find out whether there is an influence from the motor cognitive coordination training program on coordination motors and working memory. The experimental research method with the design of the pretest-posttest control group design was used in this study. The results showed that the coordination training cognitive motor training program had a significant effect on coordination motors and working memory in junior athletes. Furthermore the trainers used the cognitive training coordination training program to improve the performance of motor skills and cognitive skills in junior athletes.

(C) 2019UniversitasPendidikan Indonesia

\footnotetext{
Alamat korespondensi:

Jl. Dr.Setiabudhi No. 229 Bandung, Jawa Barat

E-mail: santoso5396@gmail.com
}

eISSN:2549-6360 


\section{PENDAHULUAN}

Olahraga permainan adalah olahraga dengan karakteristik open skill dominan, yang di mana atlet harus memprediksi kemana arah bola akan jatuh, dengan begitu atlet harus bias mengambil keputusan dengan cepat kemana dia akan bergerak (Nuri, Shadmehr, Ghotbi, \& Attarbashi Moghadam, 2013). Ada beberapa faktor yang mempengaruhi performa atlet pada saat pertandingan, beberapa penelitian mengatakan bahwa atlet dalam cabang olahraga dengan karakteristik open skill dominan, dituntut harus memiliki cognitive skillyang baik (Taylor, Nuri, Shadmehr, Ghotbi, \& Moghadam, 2012).

Cognitive skill atau bisa juga disebut fungsi kognitif memiliki peranan penting dalam pengambilan keputusan, yang dimana atlet pada cabang olahraga permainan harus memiliki kemampuan pengambilan keputusan yang (Baker, Côté, \& Abernethy, 2013). Contohnya dalam cabang olahraga bola basket pemain harus fokus pada tugasnya yaitu bersiap menembak bola, sementara pemain lawan bersiap memblokir dan menganggu konsentrasinya. Selanjutnya, mereka harus mampu dengan cepat dan efisien memilih situasi dan tindakan yang tepat di bawah tekanan pemain lawan (Oberer, Gashaj, \& Roebers, 2017). Kemampuan pengambilan keputusan salah satunya dipengaruhi oleh kapasitas working memory yang dimiliki oleh setiap individu (Bisagno \& Morra, 2018).

Kapasitas working memory adalah instrument paling tepat untuk dijadikan sebagai prediksi kemampuan pengambilan keputusan pada olahraga yang memiliki pola permainan yang kompleks (Furley \& Memmert, 2016). Selain itu atlet pada cabang olahraga permainan juga membutuhkan kemampuan yang lain seperti kelincahan, antisipasi, konsentrasi dan koordinasi yang bagus. Contohnya dalam permaianan bolavoli juga dapat dianggap sebagai olahraga dengan keterampilan yang sangat kompleks dan membutuhkan koordinasi motorik yang baik (Johan A. Pion, Job Fransen, Dieter N. Deprez, Veerle I. Segers, Roel Vaeyens, 2015).

Atlet olahraga permainan membutuhkan kemampuan koordinasi yang baik, agar dapat lebih mudah melakukan gerakan yang kompleks(Çetin, Beyleroğlu, Ye, \& Suna, 2018). Di dalam olahraga permainan pada saat pertandingan, atlet harus didukung oleh mekanisme motorik yang baik, agar menghasilkan gerakan yang sempurna dan memiliki kemampuan yang baik untuk berkontak langsung dengan objek yang bergerak yaitu bola (Efthimios, 2006). Argumen ini didukung lebih lanjut oleh fakta bahwa,pada cabang olahraga permainan tidak hanya menggabungkan teknik yang kompleks, tapi juga mengharuskan menggabungkan control tubuh dan pengambilan keputusan yang baik agar bias bermain dengan efektif (Baker \& Côté, 2003).

Melihat pentingnya peranan cognitive skill dan koordinasi pada cabang olahraga permainan, maka perlu adanya sebuah metode pelatihan yang mampu meningkatkan keduanya. Diantaranya Motor Cognitive coordination training yaitu sebuah metode latihan yang dikembangkan oleh horst lutz di Jerman (Johann, Stenger, Kersten, \& Karbach, 2016). Life Kinetik adalah metode latihan psikologis modern yang sangat berkembang di Eropa Barat seperti ( Jerman, Belanda, Francis dan Spanyol ). Di negara tersebut latihan ini dilakukan secara rutin oleh para atlet baik tingkat lokal maupun profesional. Sedangkan di Indonesia metode latihan life kinetik ini tergolong baru dan belum banyak diterapkan pada proses pelatihan cabang olahraga. Padahal Life Kinetik ini memiliki manfaat yang sangat luar biasa untuk meningkatkan performa atlet, khususnya pada cabang olahraga permainan (Wolfratshauserstra, Telefon, \& Lutz, 2011).

Latihan Life Kinetik merupakan latihan otak melalui aktivitas fisik yang bisa menstimulasi sistem saraf (Lutz, 2017). Program latihan ini mengembangkan sebuah latihan multimodel yang mengkombinasikan koordinasi, kognitif, dan tugas - tugas visual dalam sebuah latihan fisik untuk melatih fungsi kognisi. Hasil latihan Life Kinetik dipandang penting untuk meningkatkan kemampuan koordinasi dan fungsi kognisi (Lauenroth, Ioannidis, \& Teichmann, 2016). Beberapa penelitian telah membuktikan bahwa kemampuan fungsi kognitif memiliki hubungan yang signifikan dalam perkembangan motorik pada anak anak dan remaja. Dalam sebuah penelitian, anak-anak dengan tingkat fungsi kognitif yang tinggi ditemukan lebih mampu melakukan tugas motorik yang kompleks, dibandingkan dengan anak anak yang memiliki status fungsi kognitif yang lebih rendah (Edwards, 2010). Maka dari itu perkembangan 
fungsi kognitif pada atlet sangat memerlukan perhatian khusus, agar dimasa yang akan datang performa yang dia miliki sesuai dengan apa yang diharapkan.

Salah satu periode terpenting memulai pengembangan keterampilan yang spesifik pada cabang olahraga adalah pada usia12 16tahun pada laki - laki dan 11 - 15 tahun untuk perempuan (Balyi \& Hamilton, 2004). Selama masa ini, atlet secara bertahap sudah siap untuk memperoleh keterampilan cabang olahraga secara keseluruhan baik teknik maupun taktik. Pada fase ini kemampuan koordinasidan kapasitas working memory sangat berperan penting pada saat pelatihan (Mark Williams, 2002). Semua keterampilan teknik dan pemahaman terkait taktik harus dikembangkan lebih lanjut agar ketika fase selanjutnya sudah memiliki kesiapan dari segi teknik maupun kemapuan pengambilan keputusan pada saat pertandingan (Helsen \& Starkes, 1999).

Dengan demikian bahwa motor coordination dan working memory sangat dibutuhkan oleh atlet pada cabang olahraga permainan, maka dari itu peneliti ingin meneliti pengaruh dari motor cognitive coordination training pada motor coordination dan working memory pada atlet junior di sekolah bola voli Generasi Indonesia Terpadu "GIT" karena menurut (Johann et al., 2016) bahwa motor cognitive coordination training bias meningkatkan kemampuan koordinasidan fungsi kognitif secara signifikan.

\section{METODE}

\section{Partisipan dan Prosedur Penelitian}

Teknik sampling nonprobability yang peneliti gunakan menggunakan pendekatan purvosive sampling yaitu teknik penentuan sampel untuk tujuan tertentu saja. Maka sempel yang dipilih adalah atlet bola voli junior dengan criteria sampel atlet learning to train stage yaitu atlet dengan usia 12 - 16 dikarenakan untuk memudahkan peneliti melakukan penelitian. Subjek dalam penelitian ini adalah atlet sekolah bola voli Generasi Indonesia Terpadu "GIT". Pemilihan sample disini juga dilandasi oleh salah satu periode terpenting memulai pengembangan keterampilan yang spesifik pada cabang olahraga adalah pada usia12 16tahun pada laki - laki dan 11 - 15 tahun untuk perempuan (Balyi \& Hamilton, 2004).

Pada penelitian ini, peneliti menerapkan 1 (satu) kelompok eksperimen dan aktivitas pada 1 (satu) kelompok kontrol. Desain yang digunakan dalam peneltian ini adalah Pretest Postest control group design (Freankle \& Wallen, 2012):

Gambar 1 Pretest - Postest

Control Group Design Design (Fraenkel \& Wallen, 2012:269)

\begin{tabular}{|c|c|c|}
\hline MCCT $(A)$ & $\begin{array}{c}\text { MOTOR } \\
\text { COORDINATION }\end{array}$ & $\begin{array}{c}\text { WORKING } \\
\text { MEMORY }\end{array}$ \\
$(B 1)$ & B2) \\
\hline $\begin{array}{c}\text { TREATMEN } \\
\text { T(A1) }\end{array}$ & $\mathrm{A} 1 \mathrm{~B} 1$ & $\mathrm{~A} 1 \mathrm{~B} 2$ \\
\hline $\begin{array}{c}\text { CONTROL } \\
(A 2)\end{array}$ & $\mathrm{A} 2 \mathrm{~B} 1$ & $\mathrm{~A} 2 \mathrm{~B} 2$ \\
\hline
\end{tabular}

Pada penelitian ini, kelompok eksperimenmenerima program latihanmotor cognitive coordination training,kelompok kontrol diberikan aktivitas program latihan $A B C$ running. Kemudian dilanjutkan dengan melakukan pretest motor coordination dan working memory. Penelitian ini dilaksanakan selama 12 treatment yang dilaksanakan 3 kali seminggu, jadi penelitian dilakukan kurang lebih selama 4 minggu. Berikut adalah langkahlangkah yang dilakukan dalam penelitan pengaruh motor cognitive coordination training terhadap motor coordination dan working memory pada atlet junior.

\section{Instrumen Penelitian}

Untuk instrument pengukuran motor coordination menurut (Sögüt, 2016) menggunakan "Körper Test Koordination" KTK consists of four test itemsyaitu: (1) Berjalan mundur tiga kali di sepanjang masing-masing dari tiga balok keseimbangan dengan lebar penurunan: 6,0, 4,5 dan 3,0 cm; Peserta diminta untuk berjalan mundur pada tiga balok balancebeam (jumlah langkah maksimum untuk setiap balok adalah 8). Skor maksimum untuk tes ini adalah 72 jadi setiap langkah itu scorenya 3.1 (2) Bergerak ke samping pada kotak kayu selama 20 detik; peserta memindahkan tubuh mereka ke samping dari satu papan ke papan lainnya dalam 20 detik.

Skor untuk tes ini adalah jumlah dari dua kali percobaan. (3) Melompat ke samping dengan dua kaki di atas balok kayu selama 15 detik; Skornya adalah jumlah dari dua percobaan. (4) Minggir dengan satu kaki di atas 
tumpukan bantal yang semakin tinggi dengan langkah berturut-turut sebesar $5 \mathrm{~cm}$ per bantal. (tinggi mulai dari 0 hingga $60 \mathrm{~cm}$ ). Skor maksimumnya adalah 78 jadi setiap balok yang diletakan skornya 6.5. Skor hasil tes yang sudah baku dari masing-masing subtes dikonversi menjadi nilai berdasarkan usia dan genderyang sering disebut MQ (motor quotients) yang menjadi dasar KTK. Dari hasil empat test itu digunakan sebagai nilai untuk koordinasi motorik anak-anak. Menurut klasifikasi penulis sebelumnya, nilai MQ normal biasanya antara 100 dan 139 dan yang berhubungan dengan koordinasi biasanya akan terus berkembang.Untuk mengukur kapasitas working memory peneliti menggunakan Foward dan Backward digit span test menurut (Kane et al., 2004) dimana sample harus menulis ulang angka yang telah disebutkan dari depan kebelakang (fowards digit visual) dan sebaliknya dari belakang ke depan (backwards digit visual). Untuk melakukan tes ini diperlukan sebuah laptop tau komputer yang memiliki aplikasi digit span test 2.1.4.

Peneliti akan menyiapkan aplikasi dengan tes yang pertama yaitu fowarddigit span test, Kemudian atlet melakukan tes mulai dari satu digit atau angka dalam bentuk visual dari ang pertama muncul sampai yang terakhir muncul, kemudian digit akana terus bertambah deret nya, setiap atletdiberikan kesempatan dua kali melakukan kesalahan, apabaila telah melakukan kesalahan dua kali secara berturut turut maka test dia anggap selesai secore akhir dilihat sebarapa banyak atlet bisa mengingat deret angka yang muncul. Setelah itu atlet melakukan tes digit span tes backward hampir sama perosedur nya hanya saja atlet harus mengurutkan deret angka dari yang terakhir muncul ke yang pertama muncul.

\section{Analisis Data}

Teknik analisis data yang digunakan untuk menganalisis data penelitian yang sudah terkumpul adalah teknik uji paired sample $t$ test dengan $p$-value $\leq 0,05$. Teknik analisis ini digunakan untuk mengetahui pengaruh motor cognitive coordination training terhadap motor koordination dan working memory pada atlet bola voli junior klub generasi indonesia terpadu "GIT". Data dalam penelitian ini berdistribusi normal dan memiliki variansi data yang homogen, yang sebelumnya sudah diolah menggunakan uji normalitasShapiroWilkpada $p$-value $\leq 0,05$ untuk uji normalitas dan levine test untuk uji homogenitas data.
Pengolahan data dalam penelitian ini dibantu dengan software SPSS v.23 for windows.

\section{HASIL DAN PEMBAHASAN}

Pada pretest kelompok eksperimen diperoleh nilai rata-rata $(\boldsymbol{\pi}=157,33)$ untuk score motor coordination dengan simpangan baku ( $\boldsymbol{\sigma}=$ 16,57) dan mengalami peningkatan pada saat posttest dengan nilai rata-rata $(\boldsymbol{\pi}=190,00)$ dengan nilai simpangan baku $(\sigma=7,76)$. Pada pretest kelompok control diperoleh nilai ratarata $(\boldsymbol{\pi}=179,86)$ untuk score motor coordination dengan simpangan baku $(\sigma=10,21)$ dan mengalami peningkatan pada saat posttest dengan nilai rata-rata $(\boldsymbol{\pi}=181,64)$ dengan nilai simpangan baku $(\boldsymbol{\sigma}=10,84)$.Pada pretest kelompok eksperimen diperoleh nilai rata-rata ( $\boldsymbol{\pi}=71,73)$ untuk nilai kapasitas working memory dengan simpangan baku $(\boldsymbol{\sigma}=6,35)$ dan mengalami peningkatan pada saat posttest dengan nilai rata-rata $(\boldsymbol{\pi}=86,40)$ dengan nilai simpangan baku $(\boldsymbol{\sigma}=5,90)$.Pada pretest kelompok control diperoleh nilai rata-rata $(\boldsymbol{\pi}$ $=76,93$ ) untuk score motor coordination dengan simpangan baku $(\boldsymbol{\sigma}=9,96)$ dan mengalami peningkatan pada saat posttest dengan nilai ratarata $(\boldsymbol{\pi}=78,00)$ dengan nilai simpangan baku $(\boldsymbol{\sigma}$ $=9,35)$.

Uji paired sampel t test dilakukan untuk melihat apakah ada perbedan antara kelompok yang diberikan program motor cognitive coordination training dan yang tidak diberikan program motor cognitive coordination training ketentuan sebagai berikut : $H_{0}$ diterima jika nilai (Sig.) > 0,05 artinya terdapat pengaruh yang signifikan program motor cognitive coordination training terhadap motor coordination atlet junior, dan $H_{0}$ ditolak jika nilai (Sig.) < 0,05.artinya tidak terdapat pengaruh yang signifikan program motor cognitive coordination training terhadap motor coordination atlet junior. $H_{0}$ diterima jika nilai (Sig.) $>0,05$ artinya terdapat pengaruh yang signifikan program motor cognitive coordination training terhadap working memory atlet junior, dan $H_{0}$ ditolak jika nilai (Sig.) < 0,05.artinya tidak terdapat pengaruh yang signifikan program motor cognitive coordination training terhadap working memory atlet junior. 
Tabel 1. Ujibeda rata - rata nilai Motor Coordination pada kelompok eksperimen

(paired sample t-test)

\begin{tabular}{|c|c|c|c|}
\hline \multicolumn{2}{|c|}{ KELOMPOK } & \multicolumn{2}{c|}{$\begin{array}{c}\text { Nilai } \\
\text { Coordination }\end{array}$} \\
\cline { 3 - 4 } & $\mathrm{T}$ & Sig. \\
\hline \multirow{2}{*}{ Eksperimen } & PRETMC & & \\
\cline { 2 - 4 } & POSTMC & -7.10 & 0,000 \\
\hline
\end{tabular}

Berdasarkan tabel 4.6 nilai sig. Motor coordination adalah $0,000<0,05$ maka $H_{0}$ ditolak. Artinya terdapat pengaruhyang signifikan programmotor cognitive coordination training terhadap motor coordination.

Tabel 2. Uji beda rata - rata nilai Working Memory pada kelompok eksperimen

(paired sample t-test)

\begin{tabular}{|c|c|c|c|}
\hline \multicolumn{2}{|c|}{} & \multicolumn{2}{c|}{ Nilai } \\
KELOMPOK & \multicolumn{2}{c|}{$\begin{array}{l}\text { Working } \\
\text { memory }\end{array}$} \\
\cline { 3 - 4 } \multicolumn{2}{|c|}{} & $\mathrm{T}$ & Sig. \\
\hline $\begin{array}{c}\text { Eksperime } \\
\mathrm{n}\end{array}$ & PRETMC & -10.971 & 0,000 \\
\cline { 3 - 4 } & POSTMC & & \\
\hline
\end{tabular}

Berdasarkan tabel 4.7 nilai sig. Nilai Working Memory adalah 0,000 $<0,05$ maka $H_{0}$ ditolak. Artinya terdapat pengaruhyang signifikan programmotor cognitive coordination training terhadap Working Memory.

\subsection{PEMBAHASAN}

Dari hasil penelitian ini dapat disimpulkan bahwa program latihan motor cognitive coordination training, memiliki pengaruh yang signifikan terhadap kemampuan koordinasi dan kapasitas working memory pada atlet bola voli junior. Penelitian ini diharapkan bisa menjadi referensi bagi para pelatih, bahwa pada cabang olahraga permainan salah satunya cabang olahraga bola voli memerlukan program khusus untuk meningkatkan kemampuan koordinasi dan kapasitas working memory atletnya. Sudah banyak penelitian menunjukan bahwa kemampuan koordinasi dan kapasitas working memory memiliki peranan penting dalam mempengaruhi performa atlet pada saat pertandingan.

Kemampuan koordinasi seseorang bukan hanya memiliki dampak pada perfomanya pada saat dia bergerak saja, akan tetapi kemampuan koordiansi bisa dijadikan penilaian untuk melihat kondisi kesehatan mental dan fungsi kognisinya (Hondt et al., 2013). Koordinasi memiliki peranan penting dalam proses perkembangan anak terutama untuk menunjang aktivitas fisik yang dilakukan sehari - hari, dimana anak yang memiliki kemampuan koordinasi yang baik mampu melakukan keterampilan gerak yang lebih baik, dibandingkan dengan anak yang memiliki keterampilan koodinasi kurang baik (Bardid, Rudd, Lenoir, Polman, \& Anderson, 2015). Kemudian kemampuan koordinasi juga mempengaruhi terhadap pola hidup anak anak, yang dimana anak yang memiliki kemampuan koordinasi yang kurang baik cenderung memiliki masalah terhadap berat badan (Maia \& Stasinopoulos, 2015). Di dalam olahraga prestasi kemampuan koordinasi sangatlah diperlukan oleh seorang atlet, agar bia mengotrol bagian tubuh atau multilimb dengan baik, yang didefinisikan sebagai kemampuan untuk mengikuti tugas gerak yang telah ditentukan dengan menggunakan kedua tangan atau kaki (Rikberg \& Raudsepp, 2011).

Program latihan motor cognitive coordination training memiliki pengaruh yang sangat signifikan terhadap kapasitas working memory pada atlet bola voli junior. Sudah banyak penelitian terkait pemberian program latihan kognitif terhadap perkembangan kapasitas working memory. Sebuah penelitian menunjukan pemberian latihan dengan menambahkan tantangan kognitif memiliki dampak yang signifikan terhadap kemampuan pengambilan keputusan pada atlet sepak bola junior (Winkler, 2017). Pelatihan yang ditambah dengan tugas kognitif memiliki pengaruh yang signifikan terhadap perkembangan fungsi kognisi anak (Lauenroth et al., 2016). Selain itu dengan pelatihan yang menggabungkan tugas gerak dan tugas kognitif dapat meningkatkan kemampuan pengambilan keputusan secara signifikan dalam mengimplementasikan taktik pada saat pertandingan (Vaeyens, Lenoir, 
Williams, Philippaerts, \& Lenoir, 2013). Kemudian dalam sebuah penelitian menujukan peningkatan yang signifikan pada kapasitas working memory atlet, setelah diberikan program latihan yang dengan tugas kognitif pada atlet sepak bola (Alesi, Bianco, Luppina, \& Palma, 2016).

Dengan demikian dapat disimpulkan bahwa program latihan yang ditambahkan dengan tugas - tugas kognitif mampu meningkatkan kapasitas working memory, yang dimana kapasitas working memory memiliki peranan yang sangat penting dalam kemampuan pegambilan keputusan. Maka dari itu program ini perlu dikembangkan lebih lanjut, agar bisa bermanfaat bagi perkembangan atlet terutama pada cabang olahraga permainan, yang dimana dituntut memiliki kemampuan kognitif yang baik.

\section{KESIMPULAN}

Kemampuan motor coordination dan working memory adalah kemampuan yang penting dimiliki oleh seorang atlet pada cabang olahraga permainan, termasuk pada cabang olahraga bola voli. Dalam penelitian ini, peneliti ingin melihat seberapa besar pengaruh dari program latihan Motor Coognitive Coordination Training terhadap peningkatan Motor Coordination dan Working Memory pada atlet bola voli junior. Hasil dari penelitian ini menunjukan adanya pengaruh yang signifikan pemberian program latihan Motor Cognitive Coordination Training terhadap perkembangan Motor Coordination, dan terdapat pengaruh yang signifikan pemberian program latihan Motor Cognitive Coordination Training terhadap Working Memory pada atlet bola voli junior.

\section{DAFTAR PUSTAKA}

Alesi, M., Bianco, A., Luppina, G., \& Palma, A. (2016). Improving Children ' $\mathrm{s}$ Coordinative Skills and Executive Functions: The Effects of a Football Exercise Program. https://doi.org/10.1177/0031512515627 527

Baker, J., \& Côté, J. (2003). Sport-Specific Practice and the Development of Expert DecisionMaking in Team Ball Sports, 12-25. https://doi.org/10.1080/1041320039018 0035

Baker, J., Côté, J., \& Abernethy, B. (2013). Learning from the Experts: Practice
Activities of Expert Decision Makers in Sport, (May), 37-41.

Balyi, I., \& Hamilton, A. (2004). Long-Term Athlete Development: Trainability in Childhood and Adolescence. Windows of Opportunity. Optimal Trainability. Training, 1-6. Retrieved from http://www.athleticsireland.ie/content/ wpcontent/uploads/2007/03/bayliLTAD200 4.pdf\%5Cnhttp://pellatrackclub.org/files /www.athleticsireland.ie_content_wpcontent_uploads_2007_03_bayliLTAD2004 .pdf

Bardid, F., Rudd, J. R., Lenoir, M., Polman, R., \& Anderson, D. I. (2015). Cross-cultural comparison of motor competence in children from, 6(July), 1-8. https://doi.org/10.3389/fpsyg.2015.0096 4

Bisagno, E., \& Morra, S. (2018). How do we learn to "kill" in volleyball?: The role of working memory capacity and expertise in volleyball motor learning. Journal of Experimental Child Psychology, 167, 128145.

https://doi.org/10.1016/j.jecp.2017.10.0 08

Çetin, O., Beyleroğlu, M., Ye, B., \& Suna, G. (2018). The effect of the exercises brain on boxers' eye-hand coordination, dynamic balance and visual attention performance., 112119.

https://doi.org/10.15561/20755279.201 8.0301

Edwards, W. H. (2010). Motor Learning and Control From Theory to Practice.

Efthimios, M. M. (2006). Ability Profile of The Elite Volleyball Player. Development, (28351), 757-770.

Furley, P. A., \& Memmert, D. (2016). Working Memory Capacity as Controlled Attention in Tactical Decision Making. Journal of Sport and Exercise Psychology, 34(3), 322-344. https://doi.org/10.1123/jsep.34.3.322

Helsen, W. F., \& Starkes, J. L. (1999). A Multidimensional Approach to Skilled Perception and Performance in Sport, 13(November 1997), 1-27.

Hondt, E. D., Deforche, B., Gentier, I., Bourdeaudhuij, I. De, Vaeyens, R., Philippaerts, R., \& Lenoir, M. (2013). Longitudinal analysis of gross motor coordination in overweight and obese children versus normal-weight peers, (February 2012), 61-67. 
https://doi.org/10.1038/ijo.2012.55

Johan A. Pion, Job Fransen, Dieter N. Deprez, Veerle I. Segers, Roel Vaeyens, R. M. P. (2015). Stature And Jumping Height Are Required In Female Volleyball, But Motor Coordination Is A Key Factor For Future Elite Success. Journal of Strength and Conditioning Research, 1480-1485. Retrieved from johan.pion@ugent.be

Johann, V. E., Stenger, K., Kersten, S., \& Karbach, J. (2016). Effects of motor-cognitive coordination training and cardiovascular training on motor coordination and cognitive functions. Psychology of Sport and Exercise, 24, 118-127. https://doi.org/10.1016/j.psychsport.201 6.01 .008

Kane, M. J., Hambrick, D. Z., Tuholski, S. W., Wilhelm, O., Payne, T. W., \& Engle, R. W. (2004). The Generality of Working Memory Capacity: A Latent-Variable Approach to Verbal and Visuospatial Memory Span and Reasoning, 133(2), 189$217 . \quad$ https://doi.org/10.1037/00963445.133.2.189

Lauenroth, A., Ioannidis, A. E., \& Teichmann, B. (2016). Influence of combined physical and cognitive training on cognition: a systematic review. BMC Geriatrics, 21-23. https://doi.org/10.1186/s12877-0160315-1

Lutz, H. (2017). Life Kinetik. Auckland, Beirut, Dubai, Hägendorf, Hongkong, Indianapolis, Kairo, Kapstadt, Manila, Maidenhead, NeuDelhi, Singapur, Sydney, Teheran, Wien Member: Meyer \& Meyer.

Maia, A., \& Stasinopoulos, M. D. (2015). Gross Motor Coordination and Weight Status of Portuguese Children Aged 6 - 14 Years, 00(September https://doi.org/10.1002/ajhb.22715

Mark Williams. (2002). Perceptual and cognitive expertise in sport, 15(8).

Nuri, L., Shadmehr, A., Ghotbi, N., \& Attarbashi Moghadam, B. (2013). Reaction time and anticipatory skill of athletes in open and closed skill-dominated sport. European Journal of Sport Science, 13(5), 431-436. https://doi.org/10.1080/17461391.2012. 738712

Oberer, N., Gashaj, V., \& Roebers, C. M. (2017). Human Movement Science Motor skills in kindergarten: Internal structure, cognitive correlates and relationships to background variables. Human Movement Science, 52, 170-180. https://doi.org/10.1016/j.humov.2017.02 .002

Rikberg, A., \& Raudsepp, L. (2011). Multidimensional Performance Characteristics in Talented Male Youth Volleyball Players, 537-548.

Söğüt, M. (2016). Gross motor coordination in junior tennis players. Journal of Sports Sciences, 34(22), 2149-2152. https://doi.org/10.1080/02640414.2016. 1211311

Taylor, P., Nuri, L., Shadmehr, A., Ghotbi, N., \& Moghadam, B. A. (2012). Science Reaction time and anticipatory skill of athletes in open and closed skill-dominated sport. European Journal of Sport, (November 2012), 37-41. https://doi.org/10.1080/17461391.2012. 738712

Vaeyens, R., Lenoir, M., Williams, A. M., Philippaerts, R. M., \& Lenoir, M. (2013). Mechanisms Underpinning Successful Decision Making in Skilled Youth Soccer Players: An Analysis of Visual Search Behaviors, (July 2013), 37-41. https://doi.org/10.3200/JMBR.39.5.395408

Winkler, W. (2017). Motor skills and cognitive training for junior soccer players, 8668(July).

Wolfratshauserstra, S. I., Telefon, E., \& Lutz, H. (2011). Science and life kinetik, 0049(0), 1-8. 